\title{
PENGEMBANGAN MULTIMEDIA PEMBELAJARAN INTERAKTIF PENDIDIKAN AKHLAK DENGAN PROGRAM PREZI \\ (Studi di SMP Muhammadiyah 2 Mlati Sleman Tahun Ajaran 2013-2014)
}

\author{
Dedi Wahyudi \\ PPS UIN Sunan Kalijaga Yogyakarta \\ e-mail: dedi_wahyudi1991@yahoo.co.id
}

\begin{abstract}
Abstrak
Proses pembelajaran Pendidikan Akhlak di SMP Muhammadiyah 2 Mlati gurunya memiliki kendala dalam memotivasi semangat belajar siswa karena metode yang digunakan hanya ceramah. Buku pegangan untuk siswa kurang mencukupi sebab hanya ada satu buku ajar yang dipegang guru sehingga siswa hanya mencatat materi-materi yang diberikan oleh guru. Maka perlu adanya metode pembelajaran yang mengatasi problem tersebut yaitu multimedia pembelajaran interaktif pendidikan akhlak dengan program Prezi yang dikembangkan berdasarkan teori pengembangan Stephen M. Alessi dan Stanley R. Trollip. Prosesnya adalah meliputi perencanaan, desain, dan pengembangan. Hasil penelitian ini yaitu produk multimedia pembelajaran interaktif pendidikan akhlak telah layak digunakan di lapangan dan dapat meningkatkan prestasi peserta didik.

Kata kunci: multimedia, pendidikan, akhlak,dan prezi
\end{abstract}

\begin{abstract}
Moral Education in the learning process of SMP Muhammadiyah 2 Mlati teachers have problems in learning motivate students because of the method used only lectures. Handbook for students are insufficient because there is only one textbook held by teachers so that students only recorded material provided by the teacher. It is necessary to address the problem of learning methods, namely the moral education of multimedia interactive learning with Prezi program development theory developed by Stephen M. Alessi and Stanley R. Trollip. The process includes planning, design, and development. The results of this study are products of multimedia interactive learning moral education has been fit for use in the field and can improve the performance of learners.
\end{abstract}

Keywords: multimedia, education, morals, and Prezi

\section{Pendahuluan}

Mata pelajaran Pendidikan Akhlak merupakan mata pelajaran yang wajib diikuti oleh semua siswa di sekolah-sekolah Muhammadiyah, khususnya dalam penelitian ini yaitu SMP Muhammadiyah 2 Mlati Sleman. Di dalam proses pembelajaran Pendidikan Akhlak di SMP Muhammadiyah 2 Mlati sebagian 
gurunya memiliki kendala dalam memotivasi semangat belajar siswa. Siswa menganggap mata pelajaran akhlak sebagai mata pelajaran yang tidak penting dan tidak menarik karena banyaknya materi yang harus dihafal dan dipahami. Selain itu, ketersediaan sumber belajar siswa berupa buku pegangan untuk siswa kurang mencukupi sebab hanya ada satu buku ajar yang dipegang guru sehingga siswa hanya mencatat materi-materi yang diberikan oleh guru. Pemahaman terhadap materi pembelajaran kurang mendalam dan menyeluruh.

Dalam proses pembelajaran sangat dibutuhkan tiga hal penting yaitu materi pembelajaran, proses pembelajaran, dan hasil pembelajarannya. Beberapa guru agama SMP Muhammadiyah 2 Mlati lebih mementingkan pada hafalan materi, tetapi kurang memperhatikan dalam membuat model proses dan hasil pembelajaran. Berdasarkan hal tersebut, benar apa yang dikatakan oleh Fazlur Rahman bahwa metode pendidikan umat Islam didominasi oleh metode hafalan dan bukan pengolahan pikiran secara kreatif (Sutrisno, 2005: 13-14). Menurut Muqowim (2012:3) Jika proses pembelajaran hanya berupa hafalan terus tanpa memberikan pendidikan softskill mengakibatkan lulusan hanya pandai menghafal pelajaran saja dan sedikit punya ketrampilan ketika sudah di lapangan kerja.

Proses pembelajaran Pendidikan Akhlak dilakukan sebagian besar dengan metode, hafalan, ceramah, dan mencatat sehingga peserta didik mengalami kejenuhan dalam proses pembelajaran. Materi pembelajaran yang begitu banyaknya hanya disampaikan ringkasannya saja oleh guru, sehingga kadang peserta didik justru bingung memahami sebuah materi pembelajaran. Bahkan kadang guru tidak mempedulikan kemampuan peserta didik karena untuk mengejar target kurikulum. Para pendidik memberi materi secara cepat, banyak, dan seolah memaksa peserta didik untuk memahami sendiri materi yang disampaikan. Kondisi seperti ini sangat tidak kondusif sehingga peserta didik kesulitan untuk mencapai hasil belajar yang diharapkannya.

Media pembelajaran yang digunakan selama ini hanyalah buku pelajaran yang jumlahnya sangat kurang mencukupi karena hanya guru yang memiliki buku tersebut, papan tulis, spidol, dan kapur tulis. Para pendidik sering menjumpai kesulitan dalam menyampaikan materi pembelajaran kepada peserta didik secara 
baik, benar, dan menarik agar materi pembelajaran mudah dipahami (observasi, 11 Januari 2012-20 Oktober 2013). Hal ini seperti diungkapkan oleh Arwiti Nur Hidayah (Wawancara, 28 September 2013) guru Pendidikan Akhlak, bahwa sekolahan sudah memiliki laboratorium multimedia dan laboratorium komputer tetapi karena sumber daya manusianya yang kurang mendukung, akhirnya kedua laboratorium tersebut tidak dapat dimanfaatkan secara maksimal. Dia juga menyampaikan keprihatinannya dengan kemampuan guru agama Islam yang tidak dapat memanfaatkan media modern yang dapat menarik perhatian siswa untuk belajar dan meningkatkan prestasi belajarnya. Menurutnya, guru-guru agama SMP Muhammadiyah 2 Mlati takut mengambil resiko merusak alat-alat multimedia sehingga mereka nyaman melakukan pembelajaran hanya dengan media spidol, papan tulis, dan buku pelajaran.

Apa yang dihasilkan dari wawancara tersebut, terlihat para guru di SMP Muhammadiyah 2 Mlati masih menggunakan cara-cara lama. Cocok dengan pendapat Renata Nummela dan Geoffrey Caine (seperti dikutip Dryden dan Vos, 2003: 78) yaitu salah satu tempat yang beroperasi dengan cara yang sama seperti 50 tahun yang lalu adalah sekolah lokal. Mereka takut mengambil resiko padahal belajar itu mengandung resiko, sekali kita berpetualang untuk belajar sesuatu yang baru, kita mengambil resiko besar di luar zona nyaman kita. Zona nyaman adalah tempat atau suasana dimana didalamnya kita memiliki semua hal yang membuat kita merasa nyaman seperti tempat, tatakrama, dan mengajar dengan gaya atau model tertentu (Potter, Terj. Ary Nilandari, 2012: 68). Mereka tidak berani mencoba cara terbaru menggunakan sistem pembelajaran multimedia interaktif, internet, atau sistem pembelajaran modern. Peserta didik hanya mampu menghafal dan mencatat materi dari guru tanpa berani untuk mengembangkannya. Padahal secara literarur, di SD pantai Tahatai di Selandia Baru,anak-anak berusia 6 tahun sudah menggunakan komputer untuk membuat CD-ROM dan merencanakan sekolah masa depan mereka sendiri. Mereka menggunakan komputer untuk mengaktifkan unit-unit pembangkit energi surya dan angin yang didesain agar setiap rumah mampu memenuhi kebutuhan energinya sendiri (Dryden dan Vos, Terj. Word ++ Translation Service, 2003: 23). Di California, Jan Davidson, 
mantan guru sekolah, dan Bob suaminya hanya bermodal awal $\$ 6.000$ dari tabungan anaknya untuk merintis perusahaan multimedia pendidikan dan berhasil menjual perusahaan tersebut senilai \$1 miliar. Di Hastings, Selandia Baru, anakanak berusia 11 tahun yang tertinggallima tahun dalam membaca, mampu mengejarnya dalam waktu delapan sampai sepuluh minggu melalui program membaca dengan bantuan pemutar suara. Padahal ketinggalan semacam ini biasanya dikejar dalam waktu 3,3 tahun (Dryden dan Vos, Terj. Word ++ Translation Service, 2003: 25). Pada tahun 1981, seorang remaja Amerika berusia 25 tahun membeli Q-DOS (Quick and Dirty Operating System) seharga $\$ 75.000$ kemudian mengembangkannya menjadi sistem operasi standar untuk komputer pribadi. Dia adalah Bill Gates, pendiri Microsoft yang kini menjadi orang kaya yang sangat dermawan (Dryden dan Vos, Terj. Word ++ Translation Service, 2003: 41).

Melihat keadaan yang seperti dijelaskan diatas, maka perlu adanya suatu metode, strategi, dan media pembelajaran akhlak yang baik, benar, praktis, dan menyenangkan sehingga dapat menyeimbangkan kecerdasan otak kiri dan otak kanan. Ketika kecerdasan otak kiri dan kanan seimbang, berarti orang tersebut memanfaatkan dua belahan otak tersebut. Belajar akan terasa lebih mudah bagi mereka yang mempunyai pilihan untuk menggunakan bagian otak yang diperlukan dalam setiap pekerjaan yang sedang dihadapi (Potter dan Hernacki, Terj. Alwiyah, 2011:38). Bukan saja pendidikan mensyaratkan otak, tetapi juga karena pendidikan memiliki tujuan mengoptimalkan otak. Tidak saja untuk aspek rasional kognitif, tetapi juga emosi, fisik, dan spiritual (Given, Terj. Lala Herawati Darma, 2007: 29). Ketika dalam proses pembelajaran ada keseimbangan antara pemanfaatan fungsi otak kiri dan otak kanan, maka proses pembelajaran menjadi menyenangkan serta tidak membosankan. Sependapat dengan yang disampaikan Elaine B. Jhonson (2007: 53) yaitu karena kapasitas yang luar biasa pada otak anak maka sekolah seharusnya menyediakan lingkungan belajar yang kaya bagi anak-anak, yang membantu otak mereka lebih kuat, kreatif, dan cepat .

Agar proses pembelajaran menjadi menyenangkan maka diperlukan strategi yang tepat, salah satu langkah untuk memiliki strategi itu adalah harus 
menguasai teknik-teknik penyajian, atau biasanya disebut metode (Roestiyah , 1991: 1). Dalam teknik pembelajaran ada yang menjadikan pendidik memiliki peran utama dalam penyajian materi pembelajaran dan ada juga yang menekankan media hasil teknologi modern seperti televisi, kaset, internet, blog, dan beberapa media lainnya. Perubahan teknologi modern yang begitu cepat bukan berarti penghalang bagi guru, melainkan menjadi tantangan yang menuntut kompetensi profesional guru yang lebih tinggi (Marno dan Idris, 2010: 21).

Seorang pendidik kadang mengalami masalah dalam menyampaikan materi dalam proses pembelajaran, maka sangat dibutuhkan alat atau media pembelajaranyang tepat, baik, efektif, dan sesuai dengan kemajuan teknologi informasi dan komunikasi. Dalam hal penggunaan alat atau media pembelajaran ada yang masih bersifat konvensional dan ada juga yang menggunakan alat bantu komputer dan internet. Melalui internet peserta didik dapat melakukan perjalanan dari kenyamanan ruang kelas mereka sendiri, bahkan perjalanan mereka akan terasa lebih nyata ketika muncul konferensi gratis dan tersedianya berbagai macam alat kolaborasi pada internet (Peters, 2011: 3-4). Penggunaan komputer dan internet bukan semata-mata untuk mengkover pemahaman kita yang sudah ketinggalan zaman, tetapi kita tetap fokus pada asumsi dasar pembelajaran bahwa apapun media yang digunakan merupakan sesuatu yang dilakukan terhadap pembelajar, dan kita harus mampu mengendalikan medium yang digunakan pembelajar tersebut untuk mengolah informasi yang telah dicernakan sebelumnya (Mejer, 2003: 242). Penggunaan multimedia komputer dan internet dalam pelajaran Pendidikan Akhlak akan sangat berguna terhadap metodologi pelajaran Pendidikan Akhlak sehingga pendidik dalam hal ini berperan sebagai fasilitator dalam proses pembelajaran.

Multimedia pembelajaran interaktif berbasis pengembangan teknologi dan komunikasi mengalami perkembangan yang sangat pesat. Wujud nyata dari perkembangan teknologi dan komunikasi dalam pembelajaran tersebut diantaranya pembelajaran dengan E-learning, pembelajaran online, dan sebagainya. Diantara para pendidik juga ada yang memanfaatkan Compact Disc (CD) untuk proses pembelajaran dengan menampilkan gambar, mind map, dan 
lainnya yang berisi materi pendidikan akhlak. Sedangkan multimedia interaktif pendidikan akhlak dalam bentuk Compact Disc (CD) yang memuat materi pembelajaran yang dapat diakses dikomputer baik secara online maupun offline masih kurang keberadaannya.

Prezi adalah menjadi tawaran utama untuk memberikan solusi dari permasalahan di atas. Program ini untuk menciptakan animasi dan konten multimedia. Desain program hadir secara konsisten di seluruh desktop dan beberapa perangkat, termasuk tablet, dan smart phone. Sehingga jika pembuatan multimedia pembelajaran Pendidikan Akhlak tersebut didesain menarik untuk pembelajaran Pendidikan Akhlak maka akan sangat efektif dan cepat dalam proses pembelajaran. Pembelajaran berbasis multimedia akan lebih menarik, tidak monoton, dan memudahkan penyampaian. Peserta didik dapat mempelajari materi pelajaran secara mandiri dengan komputer yang dilengkapi dengan program yang dibutuhkan. Berdasarkan penjelasan di atas, maka peneliti tertarik untuk mengadakan penelitian dengan melakukan inovasi terhadap media pembelajaran Pendidikan Akhlak melalui multimedia pembelajaran interaktif.

\section{Metode Penelitian dan Pengembangan}

Jenis penelitian ini termasuk penelitian dan pengembangan (research and development) yaitu model penelitian yang cukup bagus dalam memperbaiki praktik di berbagai wilayah kajian. Sugiyono (2009: 297) berpendapat Research And Development yaitu penelitian yang digunakan untuk menghasilkan produk tertentu, dan menguji keefektifan produk tersebut. Penelitian ini untuk mengembangkan multimedia pembelajaran interaktif Pendidikan Akhlak.

Instrumen yang digunakan adalah instrumen angket, wawancara, observasi, serta tes pendidikan akhlak. Angket merupakan alat pengumpul data yang berupa serangkaian pertanyaan yang diajukan pada responden untuk mendapat jawaban atau penilaian produk yang telah dibuat dari sisi isi, desain, teks, animasi, kejelasan isi, serta kemampuan untuk menumbuhkan motivasi belajar peserta didik melalui media pembelajaran interaktif Pendidikan Akhlak. Wawancara digunakan untuk menggali data mengenai ketepatan rancangan dan 
media, peneliti melakukan wawancara dan menyerahkan produk yang dibuat dan lembar evaluasi agar direvisi ahli, kemudian meminta saran dan komentar agar multimedia yang dikembangkan lebih baik. Observasi digunakan untuk melihat langsung daya tarik peserta didik saat proses uji media.Tes Pendidikan Akhlak digunakan untuk mengetahui sejauh mana hasil belajar peserta didik dengan menggunakan multimedia pembelajaran interaktif Pendidikan Akhlak.

Data dalam penelitian ini ada dua macam yaitu data kualitatif dan kuantitatif. Data kualitatif yang berupa kritik dan saran dari ahli media, ahli materi, dan peserta didik. Teknik analisis data kuantitatif dalam penelitian ini menggunakan statistik deskriptif dengan skala 5 yaitu dengan penskoran dari 1 sampai 5 menggunakan SPSS 20. Langkah analisis datanya yaitu (a) mengumpulkan data mentah, (b) penskoran, (c) skor yang diperoleh kemudian dikonversikan menjadi nilai dengan skala 5 menggunakan acuan konversi dari Sukarjo (dalam Mardika, www.mardikanyom.tripod.com/Multimedia.pdf, akses tanggal 26 Oktober 2013).

\begin{tabular}{|c|c|l|}
\hline Nilai & Interval Skor & \multicolumn{1}{|c|}{ Kriteria } \\
\hline A & $4.21 \leq \mathrm{X}$ & Sangat Baik \\
\hline B & $3.40<\mathrm{X} \leq 4.21$ & Baik \\
\hline C & $2.60<\mathrm{X} \leq 3.40$ & Cukup \\
\hline D & $1.79<\mathrm{X} \leq 2.60$ & Kurang \\
\hline E & $\mathrm{X} \leq 1.79$ & Sangat Kurang \\
\hline
\end{tabular}

Tabel 1. Konversi Skor dari Sukardjo

Berdasarkan hasil konversi skor nilai maka diperoleh nilai produk multimedia pembelajaran yang sedang diteliti dan dikembangkan. Analisis multimedia pembelajaran interaktif Pendidikan Akhlak dalam meningkatkan hasil belajar peserta didik kelompok yang menggunakan multimedia pembelajaran interaktif Pendidikan Akhlak dengan skor hasil belajar peserta didik kelompok kontrol yang menggunakan pembelajaran dengan menggunakan media cetak. Pada desain ini kelompok eksperimen menggunakan media berbasis komputer maupun menggunakan media cetak dipilih secara random. Analisis menggunakan $\mathrm{t}$ test dengan bantuan SPSS.20 


\section{Multimedia Pembelajaran Interaktif Pendidikan Akhlak}

Sebagaimana yang kita ketahui, bahwa usia pendidikan adalah setua usia umat manusia (Gunawan, 1986: 1). Pendidikan dari jaman dahulu hingga sekarang tidak berubah, yang berubah adalah teknik, teknologi, metode, dan medianya (Langgulung, 1988: 169). Menurut Undang-undang Republik Indonesia tentang Sistem Pendidikan Nasional tahun 2003, pendidikan adalah usaha sadar dan terencana untuk mewujudkan suasana belajar dan proses pembelajaran agar peserta didik secara aktif mengembangkan potensi dirinya untuk memiliki kekuatan spiritual keagamaan, pengendalian diri, kepribadian, kecerdasan, akhlak mulia, serta keterampilan yang diperlukan dirinya dan masyarakat.

Solihin dan M. Rosyid Anwar (2005:21) menjelaskan kata akhlak berasal dari bahasa arab akhlaq yang merupakan bentuk jamak dari khuluq. Secara bahasa akhlak mempunyai arti budi pekerti, tabiat, dan watak. Akhlak merupakan kehendak dan kebiasaan manusia yang menimbulkan kekuatan-kekuatan yang sangat besar untuk melakukan sesuatu.

Dalam pembelajaran atau pendidikan sangat penting sekali unsur penggunaan metode pembelajaran. Metode secara etimologi berasal dari bahasa Yunani "metodos". Kata ini terdiri dari dua suku kata: yaitu "metha” yang berarti melalui atau melewati dan "hodos" yang berarti jalan atau cara. Metode berarti suatu jalan yang dilalui untuk mencapai tujuan (Arifin, dalam Armai Arief, 2002: 40). Dalam Kamus Besar Bahasa Indonesia, metode adalah cara yang teratur dan terpikir baik-baik untuk mencapai maksud. Sehingga dapat dipahami bahwa metode berarti suatu cara yang harus dilalui untuk menyajikan bahan pelajaran agar tercapai tujuan pengajaran. Pemilihan metode pembelajaran berdasarkan tujuan apa yang ingin dicapai oleh peserta didik sesudah proses belajar mengajar, bahan pelajaran apa yang digunakan selama proses pembelajaran, dan situasi pembelajaran (Daradjat, 1996: 258-269). Dalam penelitian ini digunakan multimedia pembelajaran interaktif yang sesuai dengan tujuan Pendidikan Akhlak.

Multimedia pembelajaran interaktif dibuat berdasarkan kreatifitas guru dalam membelajarkan materi pembelajaran dengan memanfaatkan media yang 
ada. Kreatifitas tersebut dapat dipandang sebagai bentuk intellijensi, seperti yang dikatakan Gardner bahwa kreatifitas merupakan salah satu dari multiple intellegences yang meliputi berbagai macam fungsi otak (Beetlestone, Terj. Narulita Yusron, 2011: 28). Muhammad Yaumi (2012: 12) berpendapat multiple intelejensi yaitu keterampilan dan bakat yang dimiliki peserta didik untuk menyelesaikan berbagai persoalan dalam pembelajaran. Dalam multimedia pembelajaran pendidikan akhlak misalnya dicantumkan mind map materi pembelajaran, hal ini sangat bermanfaat bagi berkembangnya fungsi otak peserta didik. Sebab, mind map adalah suatu teknis grafis yang memungkinkan kita untuk mengeksplorasi seluruh kemampuan otak kita untuk keperluan berpikir dan belajar (Windura, 2008: 16). Selain mind map, dapat juga dimasukkan video pendidikan akhlak berbasis hypnoteaching dimana hal itu merupakan seni berkomunikasi baik menggunakan media atau tidak agar para peserta didik menjadi lebih cerdas. Menurut Hajar (2011: 75), dengan sugesti yang diberikan, diharapkan mereka sadar dan tercerahkan bahwa ada potensi luar biasa yang selama ini belum pernah mereka optimalkan dalam pembelajaran.

Salah satu program yang tepat digunakan untuk membuat multimedia pembelajaran interaktif yaitu Prezi. Versi yang digunakan dalam penelitian ini adalah Prezi versi 4.3.1., program ini mempunyai banyak fungsi seperi pembuatan animasi objek, membuat presentasi, animasi iklan, game, pendukung aplikasi halaman web, hingga dapat digunakan dalam pembuatan film animasi.

Prezi adalah sebuah perangkat lunak untuk presentasi berbasis internet. Selain untuk presentasi, Prezi juga dapat digunakan sebagai alat untuk mengeksplorasi dan berbagi ide di atas kanvas virtual. Prezi menjadi unggul karena program ini menggunakan Zooming User Interface (ZUI), yang memungkinkan pengguna Prezi untuk memperbesar dan memperkecil tampilan media presentasi mereka.

Prezi digunakan sebagai alat untuk membuat presentasi dalam bentuk linier maupun non-linier, yaitu presentasi terstruktur sebagai contoh dari presentasi linier, atau presentasi berbentuk peta-pikiran (mind-map) sebagai contoh dari presentasi non-linier. Pada Prezi, teks, gambar, video, dan media 
presentasi lainnya ditempatkan di atas kanvas presentasi, dan dapat dikelompokkan dalam bingkai-bingkai yang telah disediakan. Pengguna kemudian menentukan ukuran relatif dan posisi antara semua obyek presentasi dan dapat mengitari serta menyorot obyek-obyek tersebut. Untuk membuat presentasi linier, pengguna dapat membangun jalur navigasi presentasi yang telah ditentukan sebelumnya.

Prezi pada awalnya dikembangkan oleh arsitek Hungaria bernama Adam Somlai-Fischer sebagai alat visualisasi arsitektur. Misi yang dinyatakan oleh Prezi adalah untuk membuat berbagi ide menjadi lebih menarik, dan Prezi sengaja dibuat untuk menjadi alat untuk mengembangkan dan berbagi ide dalam bentuk visual yang bersifat naratif. (Anonim, http://id.wikipedia.org/wiki/Prezi, akses 1 Januari 2014)

Menurut Asnawir dan Basyiruddin Usman, (2002: 136), dalam pengembangan multimedia pembelajaran ada beberapa urutan langkah-langkah yang perlu diambil dalam mengembangkan program media:

a. Menganalisis kebutuhan dan karakteristik siswa

b. Merumuskan tujuan intruksional secara operasional dan jelas.

c. Merumuskan butir-butir materi secara terperinci yang dapat mendukung tercapainya tujuan.

d. Mengembangkan alat ukur keberhasilan

e. Menulis naskah media

f. Mengadakan tes dan revisi.

Model pengembangan multimedia pembelajaran interaktif Pendidikan Akhlak untuk peserta didik kelas VII-IX S MP Muhammadiyah 2 Mlati berangkat dari model pengembangan yang dikembangkan oleh Alessi dan Trollip (Zyainuri dan Eko Marpanaji, Jurnal Pendidikan Vokasi, Volume 2 Nomor 3, November 2012: 415-417) Model ini, mempunyai tiga atribut dan tiga fase seperti ilustrasi gambar 2 berikut ini. 


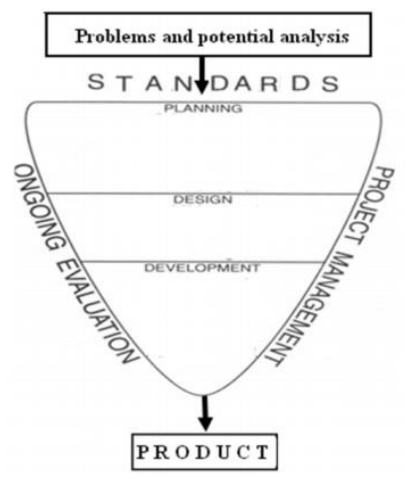

Gambar 1. Model Penelitian Riset and Development diadaptasi dari Model Alessi dan Trollip

Proses pengembangan multimedia pembelajaran interaktif Pendidikan Akhlak untuk peserta didik kelas VII SMP Muhammadiyah 2 Mlati menurut Stephen M. Alessi dan Stanley R. Trollip terlihat dalam bagan berikut ini.

Tabel 2. Proses Pengembangan Multimedia Pembelajaran Interaktif Pendidikan

Akhlak untuk

SMP Muhammadiyah 2 Mlati

\begin{tabular}{|c|c|c|c|}
\hline Perencanaan & Desain & & Pengembangan \\
\hline $\begin{array}{l}\text { 1. Mendefinisikan bidang } \\
\text { atau ruang lingkup materi. } \\
\text { 2. Mengidentifikasi } \\
\text { karakteristik siswa } \\
\text { 3. Mengidentifikasi sumber } \\
\text { daya pendukung dan } \\
\text { mengumpulkan sumber- } \\
\text { sumber atau bahan-bahan } \\
\text { 4. Menentukan kompetensi } \\
\text { dasar } \\
\text { 5. Melakukan } \\
\text { dengan guru diskusi }\end{array}$ & $\begin{array}{l}\text { 1. Mengembangkan konsep awal } \\
\text { 2. Melakukan analisis konsep dan } \\
\text { analisis tugas } \\
\text { 3. Membuat Flowcharts } \\
\text { 4. Menentukan desain tampilan } \\
\text { 5. Mengumpulkan unber- } \\
\text { sumber untuk mengisi } \\
\text { multimedia pembelajaran } \\
\text { interaktif software yang } \\
\text { 6. Menentukan dipakai } \\
\text { akan diakukan } \\
\text { 7. Evaluasi dan revisi dilakukada setiap aspek }\end{array}$ & & $\begin{array}{l}\text { 1. } \text { Menyiapkan petunjuk } \\
\text { penggunaan multimedia } \\
\text { pembelajaran interaktif } \\
\text { 2. } \text { Menyiapkan materi-materi } \\
\text { pendukung } \\
\text { 3. Membuat produk } \\
\text { 4. Melakukan uji alpha } \\
\text { (evaluasi formatif) } \\
\text { Melakukan revisi pertama } \\
\text { 5. Melakukan uji beta (evaluasi } \\
\text { formatif) } \\
\text { Melakukan revisi akhir } \\
\text { 6. Melakukan uji coba produk } \\
\text { (evaluasi sumatif) }\end{array}$ \\
\hline
\end{tabular}

\section{Hasil Penelitian dan Pengembangan}


Pengembangan multimedia pembelajaran interaktif pendidikan akhlak dengan program Prezi untuk SMP Muhammadiyah 2 Mlati, Sleman Tahun Ajaran 2013-2014 menghasilkan kesimpulan sebagai berikut:

1. Prosedur pengembangan multimedia pembelajaran interaktif Pendidikan Akhlak dengan program Prezi untuk siswa kelas VII-IX SMP Muhammadiyah 2 Mlati, Sleman tahun ajaran 2013-2014 telah melewati proses atau tahap pengembangan media sesuai dengan teori model pengembangan yang dikembangkan oleh Alessi dan Trollip yaitu tahap perencanaan, tahap desain, dan tahap pengembangan. Menurut ahli materi dan ahli media yang bertugas memvalidasi dan merevisi produk multimedia pembelajaran interaktif pendidikan akhlak dengan program Prezi versi 4.3.1 untuk SMP Muhammadiyah 2 Mlati Sleman Tahun Ajaran 2013-2014 yaitu produk ini termasuk dalam kategori sangat baik untuk aspek pembelajaran dengan skor 4,50; termasuk dalam kategori baik untuk aspek isi materi pembelajaran dengan skor 3,92; dan termasuk dalam kategori sangat baik untuk aspek media dengan skor 4,80. Berdasarkan validasi dari ahli materi dan ahli media maka produk multimedia pembelajaran interaktif pendidikan akhlak dengan program Prezi untuk SMP Muhammadiyah 2 Mlati Sleman Tahun Ajaran 2013-2014 dinyatakan layak untuk digunakan dan dikembangkan dalam proses pembelajaran pendidikan akhlak di lapangan.

2. Keberhasilan pengembangan multimedia pembelajaran interaktif Pendidikan Akhlak dengan program Prezi untuk siswa kelas VII-IX SMP Muhammadiyah 2 Mlati Sleman tahun ajaran 2013-2014 dalam meningkatkan prestasi siswa yaitu mampu meningkat prestasi peserta didik berupa tercapainya batas KKM (Kriteria Ketuntasan Minimal) pelajaran pendidikan akhlak yaitu semuanya diatas 75. Peserta didik yang menggunakan multimedia pembelajaran interaktif pendidikan akhlak tuntas 100\%. Pada kelas VII karena nilai -t hitung < -t tabel $(-10,170<-2,030)$ dan $\mathrm{P}$ value $(0,000)<0,050$; pada kelas VIII Oleh karena nilai $-\mathrm{t}$ hitung < -t tabel $(-10,170<-2,030)$ dan $\mathrm{P}$ value $(0,000)<0,050$; dan pada kelas IX karena nilai -t hitung < -t tabel $(-10,170<-2,030)$ dan $\mathrm{P}$ value $(0,000)<0,050$ maka 
$\mathrm{H}_{0}$ ditolak, artinya bahwa Ada perbedaan yang signifikan antara rata-rata nilai pendidikan akhlak dengan metode ceramah dan rata-rata nilai pendidikan akhlak dengan multimedia pembelajaran interaktif pendidikan akhlak. Kemudian karena ada perbedaan, maka kemudian dilihat rata-rata mana yang lebih tinggi dengan melihat nilai Mean pada Paired Samples Statistik, atau pada t hitung, $t$ hitung negatif berarti rata-rata nilai dengan menggunakan metode ceramah lebih rendah daripada menggunakan multimedia pembelajaran interaktif pendidikan akhlak.

Selain meningkatkan kualitas peserta didik dalam pendidikan akhlak dari segi kognitif, produk multimedia pembelajaran interaktif pendidikan akhlak dengan program Prezi versi 4.3.1 untuk SMP Muhammadiyah 2 Mlati Sleman Tahun Ajaran 2013-2014 ini mampu meningkatkan kualitas pendidikan akhlak dari segi afektif dan psikomotor, diantaranya peserta didik semakin mudah termotivasi dan bersemangat untuk mengikuti proses pembelajaran pendidikan akhlak serta peserta didik semakin mudah mencari materi pendukung dari berbagai sumber. Peserta didik juga semakin santun dan semakin berakhlak mulia.

3. Faktor-faktor pendukung pengembangan multimedia pembelajaran interaktif Pendidikan Akhlak dengan program Prezi untuk siswa kelas VII-IX SMP Muhammadiyah 2 Mlati Sleman tahun ajaran 2013-2014 yaitu tersedianya laboratorium multimedia dan komputer; tersedianya jaringan internet di sekolah; serta adanya kompetensi dan kesadaran guru pendidikan akhlak untuk untuk menggunakan media pembelajaran.

Dari ketiga poin tersebut menunjukkan keunggulan pembelajaran pendidikan akhlak menggunakan multimedia pembelajaran interaktif berbasis Prezi. Namun, sebaik apapun program prezi dalam proses pengembangan multimedia pembelajaran pendidikan akhlak, tetapi kekurangannya tidak mampu menggantikan peran guru dalam proses transfer nilai. Padahal tranfer nilai, karakter, akhlak dari guru sangat diperlukan oleh peserta didik.

\section{Rekomendasi}


Dari hasil penelitian dan pengembangan multimedia pembelajaran intera serta kesimpulan dari peneliti dan dengan segala kerendahan hati, peneliti akan mengajukan beberapa rekomendasi yang sekiranya dapat dijadikan bahan pembahasan dan kajian lebih lanjut. Dalam rangka pengembangan keilmuan pendidikan. Adapun rekomendasi tersebut adalah:

1. Bagi Sekolah

a. Hendaknya sekolah lebih memanfaatkan kembali fasilitas yang ada di sekolah terutama fasilitas internet dan laboratorium multimedia maupun laboratorium komputer untuk proses pembelajaran peserta didik khususnya pendidikan akhlak

b. Perlu adanya training atau kursus lanjutan pembuatan media pembelajaran yang menarik bagi guru-guru SMP Muhammadiyah 2 Mlati khususnya guru pendidikan akhlak

2. Bagi Guru

Hendaknya meningkatkan kemampuannya dalam membuat multimedia pembelajaran untuk meningkatkan prestasi peserta didik dan meningkatkan motivasi peserta didik. Produk multimedia yang ada hendaknya diperbaiki dan disempurnakan sesuai dengan perkembangan zaman.

3. Bagi siswa

Peserta didik hendaknya menambah wawasannya dengan cara memperhatikan penjelasan dari guru juga berlatih mencari informasi-informasi pendukung dari sumber-sumber lainnya misalnya internet.

\section{Daftar Pustaka}

Arief, Armai. 2002.Pengantar Ilmu dan Metodologi Pendidikan Islam. (Jakarta: Ciputat Pers)

Arifin, M. 1966. "Ilmu Pendidikan Agama Islam", (Jakarta: Bumi Aksara) dalam Arief, Armai. 2002. Pengantar Ilmu dan Metodologi Pendidikan Islam. (Jakarta: Ciputat Pers)

Asnawir dan Basyiruddin Usman. 2002. Media Pembelajaran. (Jakarta: Ciputat Pers) 
Barbara K. Given. 2007. Brain Based Teaching: Merancang Kegiatan Belajar Mengajar yang Melibatkan Otak Emosional, Sosial, Kognitif, kinestetis, dan Reflektif. Terj. Lala Herawati Darma. (Bandung: Kaifa)

Bobby De Potter dan Mike Hernacki. 2011. Quantum Learning: Membiasakan Belajar Nyaman dan Menyenangkan. Terj. Alwiyah Abdurrahman. (Bandung: Kaifa)

Bobby De Potter. 2012.Quantum Teaching: Mempraktikkan Quantum Learning di Ruang-ruang Kelas. Terj. Ary Nilandari. (Bandung: Kaifa)

Daradjat, Zakiah. 1996. Metodologi Pengajaran Agama Islam. (Jakarta: Bumi Aksara)

Dave Mejer. 2003. The Accelerated Learning Book: Panduan Kreatif dan Efektif Merancang Program Pendidikan dan Pelatihan. Terj. Rahmani Astuti. (Bandung: Kaifa)

Elaine B. Jhonson. 2007. Contextual Teaching and Learning: Menjadikan Kegiatan Belajar Mengasyikkan dan Bermakna. Terj.Ibnu Setiawan. (Bandung: MLC)

Florence Beetlestone, Creative Learning: Strategi Pembelajaran untuk Melestarikan Kreatifitas Siswa. Terj. Narulita Yusron. (Bandung: Nusa Media)

Gordon Dryden dan Jeannette Vos. 2003. Revolusi Cara Belajar (Learning Revolution): Belajar Akan Efektif Kalau Anda dalam Keadaan Fun Bagian 1 Keajaiban Pikiran. Terj. Word ++ Translation Service. (Bandung: Kaifa)

Gunawan, Ary. 1986. Kebijakan-kebijakan Pendidikan di Indonesia. (Jakarta: Bina Aksara)

Hajar, Ibnu. 2011. Hypno Teaching: Memaksimalkan Hasil Proses Belajar Mengajar dengan Hipnoterapi. (Yogyakarta: Diva Press)

Langgulung, Hasan. 1988. Pendidikan Islam Menghadapi Abad ke 21. (Jakarta: Pustaka Al Husna)

Laurence Peters. 2011. Pendidikan Global: Menggunakan Teknologi untuk Memperkenalkan Dunia Global Kepada Para Siswa. Terj. Ririn Sjafriani. (Jakarta: Indeks)

Marno dan M. Idris. 2010. Strategi dan Metode Pengajaran: Menciptakan Keterampilan Mengajar yang Efektif dan Edukatif. (Yogyakarta: Ar Ruzz Media) 
Muqowim. 2012.Soft Skills Guru. (Yogyakarta: Insan Madani)

Observasi mini riset tanggal 11 Januari 2012 sampai 20 Oktober 2013 di SMP Muhammadiyah 2 Mlati Sleman

Prezi, http://id.wikipedia.org/wiki/Prezi diakses tanggal 1 Januari 2014

Roestiyah,. 1991. Strategi Belajar Mengajar, Salah Satu Unsur Pelaksanaan Strategi Belajar Mengajar: Teknik Penyajian (Jakarta: Rineka Cipta) ${ }^{1}$

Solihin dan M. Rosyid Anwar, M. 2005. Akhlak Tasawuf: Manusia, Etika, dan Makna Hidup. (Bandung: Nuansa)

Sugiyono. 2009.Metode Penelitian Kualitatif, Kuantitatif, dan R\&D. (Bandung: Alfabeta)

Sukardjo. 2005. "Evaluasi pembelajaran: Diktat mata kuliah evaluasi pembelajaran". (Prodi TP PPs UNY: Tidak diterbitkan, 2005) dalam Nyoman Mardika,I. Pengembangan Multimedia Dalam Pembelajaran Kosakata Bahasa Inggris Di SD dalam http://mardikanyom.tripod.com/Multimedia.pdf . Diakses tanggal 26 Oktober 2013.

Sutrisno. 2005. Revolusi Pendidikan di Indonesia: Membedah Metode dan Teknik Pendidikan Berbasis Kompetens. (Yogyakarta: Ar Ruzz)

Undang-undang Republik Indonesia Nomor 20 Tahun 2003 tentang Sistem Pendidikan Nasional

Wawancara mini riset dengan Arwiti Nur Hidayah, S.Pd.I, Guru Pendidikan Akhlak SMP Muhammadiyah 2 Mlati, pada tanggal 28 September 2013

Windura, Sutanto. 2008.Mind Map Langkah Demi Langkah: Cara Paling Mudah dan Benar Mengajarkan dan Membiasakan Anak Menggunakan Mind Map Untuk Meraih Prestasi. (Jakarta: PT Elex Media Komputindo)

Yaumi, Muhammad. 2012. Pembelajaran Berbasis Multiple Intelligences, (Jakarta: Dian Rakyat)

Zyainuri dan Eko Marpanaji. 2012. "Penerapan E-Learning Moodle untuk pembelajan siswa yang melaksanakan prakerin", Jurnal Pendidikan Vokasi: Asosiasi Dosen dan Guru Vokasi Indosesia dan Program Pascasarjana Universitas Negeri Yogyakarta, Volume 2, Nomor 3, November 2012 